\title{
Assessment for Retreatment with Trans arterial Chemoembolization Score Effectiveness for Selecting Hepatocellular Carcinoma Patients Undergoing Repeated Therapy (ART Score Predicting Repeated TACE Impact on Overall Survival)
}

Ummi Maimunah ${ }^{1 *}$, Frida Lorita Hafidasari Pitoyo ${ }^{2}$, Hartono Yudi Sarastika ${ }^{3}$, Iswan Abbas Nusi ${ }^{1}$, Herrry Purbayu ${ }^{1}$, Titong Sugihartono ${ }^{1}$, Ulfa Kholili ${ }^{1}$, Budi Widodo ${ }^{1}$, Muhammad M iftahussurur ${ }^{1}$, Husin Thamrin ${ }^{1}$, A mie Vidyani ${ }^{1}$, Poernomo Boedi Setiawan ${ }^{1}$

${ }^{1}$ Gastroentero-Hepatology Division, Department of Internal Medicine, Faculty of Medicine-Dr. Soetomo Teaching Hospital, Universitas Airlangga, Surabaya 60131, Indonesia

${ }^{2}$ Department of Internal Medicine, Faculty of Medicine-Dr. Soetomo Teaching Hospital, Universitas Airlangga, Surabaya 60131, Indonesia

${ }^{3}$ Interventional Radiology Division, Department of Internal Medicine, Faculty of Medicine-Dr. Soetomo Teaching Hospital, Universitas Airlangga, Surabaya 60131, Indonesia

Article History:

ABSTRACT

Repeated transarterial chemoembolization (TACE) treatment is often needed to increase tumor response and survival of unresectable hepatocellular carcinoma ( $\mathrm{HCC}$ ) patients. However, not all patients experience similar benefit from retreatment. This study aimed to determine the effectivity of the Assessment for Retreatment with TACE (ART) score and clinical determinant in predicting repeated TACE impact on overall survival (OS). This study was a retrospective analysis towards HCC patients undergoing at least 2 TACE sessions was performed. The ART score was calculated one day before each repeated TACE session, and patients were divided into 0-1.5 and $\geq$ 2.5 groups. Out of thirty-two HCC patients, 59.4\% ( $n=19)$ patients revealed ART score $0-1.5$ points, while $40.6 \%(n=13)$ patients had score $\geq 2.5$ points prior to TACE- 2 session. Median OS of the whole subject was 7.6 months (95\% Cl: 5.9-9.3) with overall 1-year survival rate of $28.2 \%$. The ART score was found to be a significant predictor

\section{INTRODUCTION}

The most common hepatitis infection in Indonesia is hepatitis B infection that is caused by hepatitis B viral (HBV) (1). O ne of the effects of hepatitis $B$ diseases is hepatocellular carcinoma (HCC) (2). Transmission of HBV is parenteral, in contact with blood or other body fluids $(3,4)$. In addition, intra-familial transmission is a potential source of HBVinfected patients (5). HBV acquisition in early life is mostly asymptomatic but associated with a particular risk of developing chronic infection (6).

Hepatocellular carcinoma (HCC) is the most frequent primary liver cancer mainly found in patients with chronic liver disease and cirrhosis, ranking the sixth most common cancer and the fourth cause of cancer related-death worldwide in 2018 (7). Other causes that can develop HCC are non-alcoholic fatty liver disease, aflatoxin, alcohol, and genetic factors (8). The highest incidence is obtained in China (55\%) followed by sub-Saharan A frica due to high prevalence of HBV infection (9). Although there were no exact data yet, $\mathrm{HCC}$ incidence in Indonesia is estimated to be high since the basic health survey reported that Indonesia had moderate endemicity of HBV infection (10). The incidence and mortality of $\mathrm{HCC}$ in the world are quite similar per year (about 841,000 new cases and 782,000 deaths), which point out poor prognosis of this disease $(7,11)$.

Treatment allocation and prognosis of HCC patients are not only affected by tumor itself but also the remaining liver
Revised: 10.04 .2020

Accepted: 08.05.2020

of survival (median OS and ART score of 0-1.5 vs. $\geq 2.5$ points; 11 vs 4.9 months; respectively, $P=0.020$ ), although in sub-analysis according to time intervals ( $\leq 90 \mathrm{vs.}>90$ days) showed no statistically difference that might be due to low sample size. Moreover, AFP levels $>200 \mathrm{ng} / \mathrm{mL}$ was the only one clinical determinant that associated with poor survival. The ART score has potential to be a significant predictor of OS as well as AFP levels for HCC patients who undergo retreatment with TACE.

Keywords: HCC, TACE, ALBI grade, survival

Correspondance:

Ummi Maimunah, MD

Department of Internal Medicine, Faculty of Medicine-Dr. Soetomo

Teaching Hospital, Universitas Airlangga, Surabaya 60131, Indonesia

Email: umima@gmail.com

DOI: $10.31838 /$ srp.2020.5.32

@Advanced Scientific Research. All rights reserved

function (12). The Barcelona Clinic Liver Cancer Classification (BCLC) recommends potentially curative treatment, including hepatic resection ( $H R$ ), orthotopic liver transplantation (OLT), and radiofrequency ablation (RFA) for the early stage of HCC $(13,14)$. Unfortunately, the majority of $\mathrm{HCC}$ patients are diagnosed at relatively latestage (9), so the treatment of choice is limited to palliative approach, such as transarterial chemoembolization (TACE) and systemic therapy (13).

TACE is the most widely used treatment for unresectable HCC (15), particularly is recommended as standard of care for multinodular asymptomatic tumors without macrovascular invasion or extrahepatic metastasis (intermediate HCC, BCLC stage B) to provide local tumor control and prolong survival $(13,14)$. However, TACE outcomes are varied widely and difficult to predict since an intermediate-stage consisting of heterogeneous populations in terms of tumor burdens and liver function (12). M ostly, patients require repeated therapy at least three times to gain optimal radiological response (16). Unfortunately, retreatment may potentially induce liver damage in which diminish survival advantage, especially in patients with underlying cirrhosis (17). Thus, objective medical tools are required to select the best candidates who will benefit from retreatment and obviate further therapy or switching to other modalities in patients who will not ben efit. 
The assessment for retreatment with TACE (ART) score is one of the prognostic scoring system that has been developed to predict patient survival after TACE-2 session. This score consists of parameter related to previous TACE effect on tumor (radiologic responses) and liver functions (increase of AST $>25 \%$ and Child-Pugh score from baseline). The ART score $\geq 2.5$ or higher is associated with poor prognosis, thus repeated TACE sessions should be obviate (18). To date, validation of an ART score in 8 published studies reported various results, therefore its applicability could not be generalized (19-26). To our knowledge, there are no validation studies of an ART score usage in Indonesian population. Thus, the primary endpoint of this study was to determine the effectiveness of an ART score in predicting survival outcomes in our population. The secondary endpoint was to determine the clinical determinants associated with survival.

\section{MATERIALSAND METHODS}

This study used retrospective observational study design, conducted from January $1^{\text {st }}, 2013$ to January $31^{\text {st }} 2019$ in Dr. Soetomo Hospital (Surabaya, Indonesia). In our database, thirty-six patients were treated with at least 2 conventional TACE sessions as first-line therapy, but only 32 patients were recruited for the final analysis. Theinclusion criteria were age $>18$ years old at TACE- 1 session and classified as BCLC stage $A$ or B with preserved liver function (Child-Pugh class A or B7 without any ascites). Patients with TACE interval longer than 90 days were not excluded and would be sub-analyzed. Patients were excluded if they received $\mathrm{HCC}$ treatment other than TACE (such as HR, OLT, RFA, etc.) and had malignancy at other part of the body.

We collected demography, laboratory, and clinical data from medical record database one day before each TACE session. Radiologic tumor response was evaluated by comparing computerized tomography scan one month before and 4-8 weeks after TACE using the M odified Response Evaluation Criteria in Solid Tumors (mRECIST). Objective tumor response was defined as partial response (PR), while the absence of objective tumor response was defined as stable disease and progressive disease (14).

ART score calculation and OS

ART score was the sum of points from all three variables consisting of radiological tumor response (absent: 0 point; presents: 1 point), the AST increase $>25 \%$ (absent: 0 point; present: 4 point), and Child Pugh score increase (absent: 0 point; 1 point: 1.5 points; $\geq 2$ points: 3 points). Patients were divided into two prognosis groups, $0-1.5$ and $\geq 2.5$ points (18). The ART score was calculated one day prior to TACE2, TACE-3, and TACE-4, respectively. Baseline values (before TACE-1) of each variable in the ART score was used as a reference (19). Overall survival in this study was defined as a time from a day prior to TACE-2 session until death or last follow-up. The survival observation period for each patient was done at least one year longer after the TACE-2 procedures. Tracking by phone or district office visitation was performed for patients who lost to follow-up for less than one year to provide survival data.
Ethical clearance was approved by the Ethics Committee of Dr. Soetomo Hospital (Surabaya, Indonesia). Informed consent was not performed as not required for this study.

Statistical Analysis

The SPSS statistical software package version 23 (SPSS, Inc., Chicago, I L, USA) was used for data analysis. The categorical data were displayed as frequency and percentage and analyzed using Chi-squared test (Fisher's exact test), whereas continuous data were presented as mean $\pm \mathrm{SD}$ or median (range) and analyzed using independent t-test. Survival analyzes were performed using the Kaplan-Meier method and reported as median OS. Univariate analyses of clinical determinant variables that were associated with OS were performed using the log rank test. Variables that were significant ( $p<0.25$ ) were entered to multivariate Cox regression and reported as hazard ratio. $P$ value that was considered to be significant was $<0.05$.

\section{RESULTS}

Baseline patients and disease characteristics prior to the TACE- 1 and the TACE-2 are shown in Table 1 . Of the thirtytwo patients recruited, 24 (75\%) patients weremale, mean age of $56.7 \pm 11.9$ years old, and mostly had underlying HBV infection (59.4\%). Themedian number of TACE sessions was 2 (range 2-5). The median time interval of all population between the TACE-1 and TACE-2 session was 79 days (range 29-356), while 51.5 days (range 29-85) for thosewho repeated TACE within 90 days and 164 days (range 92-356) for those with more than 90 days. The most widely used of chemotherapeutic agents was doxorubicin (62.5\%), followed by doxorubicin/carboplatin combination (28.2\%) and cisplatin (9.3\%).

Table 1: Baseline patients and disease characteristics

\begin{tabular}{|c|c|c|}
\hline Variable & $\begin{array}{l}n \text { or mean } \pm S D \text { or } \\
\text { median }\end{array}$ & $\begin{array}{l}\text { Range or } \\
\%\end{array}$ \\
\hline \multicolumn{3}{|l|}{ Before the } \\
\hline Age (years) & $56.7 \pm 11.9$ & $34-76$ \\
\hline \multicolumn{3}{|l|}{ Sex } \\
\hline Male & 24 & 75 \\
\hline Female & 8 & 25 \\
\hline \multicolumn{3}{|l|}{ Etiology } \\
\hline HBV & 19 & 59.4 \\
\hline $\mathrm{HCV}$ & 5 & 15.6 \\
\hline Non $B / C$ & 8 & 25 \\
\hline Tumor size $(\mathrm{cm})$ & 9.6 & $3.3-25$ \\
\hline$<5$ & 3 & 9.4 \\
\hline $5-10$ & 15 & 46.8 \\
\hline$\geq 10$ & 14 & 43.7 \\
\hline \multicolumn{3}{|l|}{ Tumor number } \\
\hline Single & 21 & 65.6 \\
\hline M ultiple & 11 & 34.4 \\
\hline \multicolumn{3}{|l|}{ Tumor extent } \\
\hline Unilobar & 25 & 78.1 \\
\hline Bilobar & 7 & 21.9 \\
\hline \multicolumn{3}{|l|}{ BCLC stage } \\
\hline A & 20 & 62.5 \\
\hline B & 12 & 37.5 \\
\hline
\end{tabular}




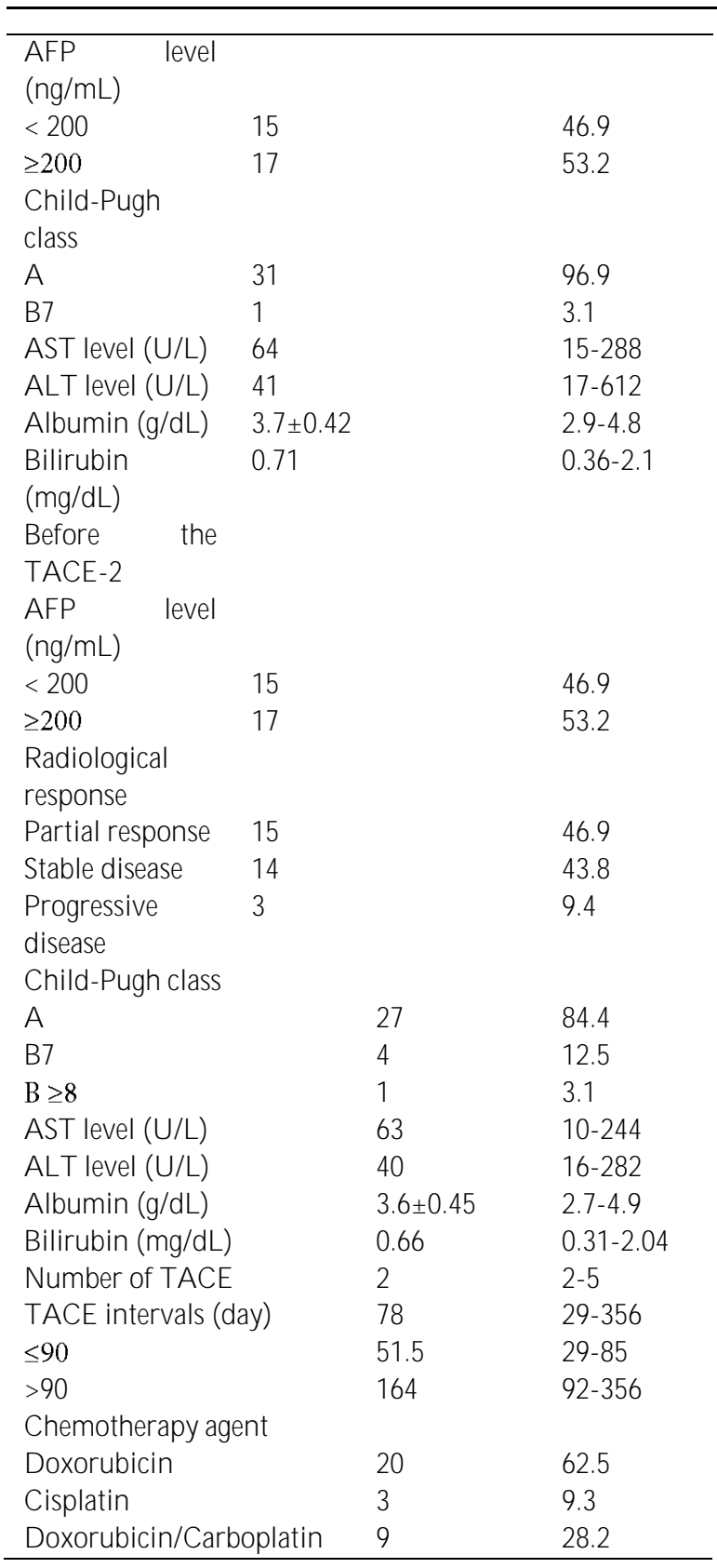

\section{BeforeTACE-1}

M ost of patients were classified as Child-Pugh A (96.65) and staged with BCLC A (62.5\%). Baselineabnormal liver enzyme test mostly found in patients with $\mathrm{HBV}$ infection (data not shown). M edian tumor size was $9.6 \mathrm{~cm}$ (range $3.3-25 \mathrm{~cm}$ ) with $90.6 \%$ patients had tumor size beyond Milan's criteria (single $\mathrm{HCC} \leq 5 \mathrm{~cm}$ or up to $3 \mathrm{HCCs} \leq 3 \mathrm{~cm}$ ). The AFP values $\geq 200 \mathrm{ng} / \mathrm{mL}$ was obtained in 17 patients $(53.2 \%)$. There were no statistically differences between AFP levels and tumor size $(p=0.138)$, tumor number $(p=0.709)$, and tumor extension $(p=1.000)$.

\section{BeforeTACE-2}

Before TACE-2 session, seven patients (21.8\%) experienced a Child-Pugh increase by 1 point, whereas 14 patients (43.7\%) remained unchanged and 11 patients (34.4\%) showed a decrease of the Child-Pugh score by 1 point. N o statistically difference in liver function biochemistry between before the TACE- 1 and TACE- 2 was observed [AST $(p=0.938)$, ALT ( $p$ $=0.122)$, albumin $(p=0.57)$, and bilirubin $(p=0.105)$ levels). Objective radiological response was obtained in 15 patients (46.9\%). The number of patients with AFP levels $\geq 200 \mathrm{ng} / \mathrm{mL}$ before TACE-1 and TACE- 2 was similar. No significant correlation was found between AFP levels and radiological response $(p=0.821)$.

\section{Overall survival and ART score}

TheART scorecalculation is presented in Table2. During the observational period, 29 patients (90.6\%) died and 3 patients $(9.4 \%)$ were still alive. The median OS of the whole population was 7.6 months $(95 \% \mathrm{Cl}: 5.9-9.3)$ with the overall 1- and 3-year survival was $28.2 \%$ and $3.2 \%$, respectively. Nineteen patients (59.4\%) had an ART score of 0-1.5 points, while 13 patients $(40.6 \%)$ had an ART score of $\geq 2.5$ points. Figure 1 shows that the ART score was found to be a significant predictor of survival (median OS an ART score of $0-1.5$ vs. $\geq 2.5$ points: 11 vs 4.9 months; $P=0.020$ ). However, sub-analysis in both patients with time interval $\leq 90$ days and those who exceeded 90 days showed no significant difference in $\mathrm{OS}$ (Figures 2 and 3 ). In addition, between 2 groups of ART score beforeTACE-3, there was also no statistically difference in OS ( $P=0.657)$. It might be due to the small sample size. Although not analyzed statistically due to low sample $(n=4)$, higher ART score beforeTACE- 4 revealed shorter OS than in lower ART group.

Tabel 2: ART score and OS for each TACE retreatment

\begin{tabular}{llll}
\hline ART groups & total, $\mathbf{n}(\%)$ & Median OS (months) & p value \\
\hline $\begin{array}{l}\text { Before TACE-2 } \\
\text { a. All TACE intervals }\end{array}$ & & & \\
Low (0-1.5 points) & $19(59.4 \%)$ & 11 & \\
High ( $\geq 2.5$ points) & $13(40.6 \%)$ & 4.9 & 0.020 \\
b. TACE intervals $\leq 90$ days & & & \\
Low (0-1.5 points) & $13(65 \%)$ & 11 & 0.104 \\
High ( $\geq 2.5$ points) & $7(35 \%)$ & 7.1 & \\
C. TACE intervals $>90$ days & & & \\
Low (0-1.5 points) & $6(50 \%)$ & 5.6 & \\
High ( $\geq 2.5$ points) & $6(50 \%)$ & 3.4 & \\
Before TACE-3 & & & \\
\hline
\end{tabular}




\begin{tabular}{llll}
\hline Low $(0-1.5$ points) & $8(72.3 \%)$ & 6.5 & 0.657 \\
High ( $\geq 2.5$ points) & $3(27.3 \%)$ & 7.4 & \\
Before TACE-4 & & & \\
Low (0-1.5 points) & $1(25 \%)$ & 14.5 & \\
High ( $\geq 2.5$ points) & $3(75 \%)$ & 9.6 & \\
\hline
\end{tabular}

${ }^{a} A R T$ score could not be calculated in 3 patients due to incomplete data (AST, albumin, bilirubin)

${ }^{\mathrm{b} A R T}$ score could not be calculated in 1 patients due to incomplete data for counting Child Pugh score (albumin, bilirubin)

\section{Analysis of prognostic factors associated with survival}

The results of univariate and multivariate analysis of the prognostic factors for OS are summarized in Table 3. Our univariate analysis revealed significant difference in OS for AFP levels beforeTACE-1 session (OSAFP levels $<200$ vs. $\geq 200 \mathrm{ng} / \mathrm{mL}$ : 9.8 vs. 7.2 months, $P=0.0270$ ) and ChildPugh increase prior to TACE-2 session (absent vs. present: 9.4 vs. 7.2 months, $P=0.038$ ). M ultivariate analysis using stepwise Cox regression to all prognostic variables with $p$ value $<0.25$ was obtained that baseline AFP was an independent predictor associated with poor survival (HR 2.35 [95\% Cl 1.075-5.118]; $P=0.032$ ). Kaplan M eier Curve of an AFP is shown in Figure 4.

\section{DISCUSSION}

The non-curative management for unrespectable stage $\mathrm{HCC}$ is still a major challenge to date. Although the treatment modalities for this stage have been progressed rapidly, the OS of HCC patients in fact is still poor. As a palliative treatment, TACE has been widely performed in non-surgery cases, particularly for intermediate stage $(13,14,17)$. TACE consists of intra-arterial chemoinfusion followed by embolization of the tumor-feeding vessels which will result in astrong cytotoxic and ischemic effect that decrease tumor progressivity and prolongation survival (17).

As mentioned before, prognosis of HCC patients is affected by tumor burdens and severity of liver dysfunction. In this study, we found that median OS of all population of 7.6 months was shorter than those in other similar studies (longer than 20 months) (18-26). We suggested that this large survival discrepancy might be due to larger tumor size in our population $(90.6 \%$ had tumor size larger than $5 \mathrm{~cm}$, even $43.7 \%$ had larger than $10 \mathrm{~cm}$ ), although univariate

Tabel 3: A nalysis of prognostic factors before and after TACE-1 procedure

\begin{tabular}{|c|c|c|c|c|c|c|c|}
\hline \multirow{2}{*}{ Variable } & \multirow{2}{*}{$n=32$} & \multicolumn{2}{|c|}{ OS (months) } & \multirow{2}{*}{$\begin{array}{l}\text { p value } \\
\text { (Log-rank) }\end{array}$} & \multicolumn{3}{|c|}{ Cox Regression } \\
\hline & & median & $95 \% \mathrm{Cl}$ & & p value & $\mathrm{HR}$ & $95 \% \mathrm{Cl}$ \\
\hline \multicolumn{8}{|l|}{ Sex } \\
\hline Male & 24 & 7.5 & $6.180-8.820$ & 0.269 & & & \\
\hline Female & 8 & 9.8 & $0.000-22.551$ & & & & \\
\hline \multicolumn{8}{|l|}{ Age (years) } \\
\hline$<60$ & 19 & 7.5 & $4.372-10.628$ & 0.915 & & & \\
\hline$\geq 60$ & 13 & 8.3 & $6.421-10.179$ & & & & \\
\hline \multicolumn{8}{|l|}{ Etiology } \\
\hline HBV & 19 & 7.5 & $4.829-10.171$ & 0.694 & & & \\
\hline $\mathrm{HCV}$ & 5 & 11 & $3.700-18.300$ & & & & \\
\hline Non $B / C$ & 8 & 9.8 & $0.000-20.056$ & & & & \\
\hline \multicolumn{8}{|l|}{ Tumor size $(\mathrm{cm})$} \\
\hline$<5$ & 3 & 2.4 & $1.760-3.040$ & 0.880 & & & \\
\hline $5-10$ & 15 & 8.7 & $6.302-11.098$ & & & & \\
\hline$>10$ & 14 & 7.5 & $2.550-12.450$ & & & & \\
\hline \multicolumn{8}{|l|}{ Tumor number } \\
\hline Single & 21 & 8.3 & $5.833-10.767$ & 0.519 & & & \\
\hline Multiple & 11 & 7.6 & $3.500-11.700$ & & & & \\
\hline \multicolumn{8}{|l|}{ Tumor extent } \\
\hline Unilobar & 25 & 9.4 & 3.851-14.949 & 0.058 & & & \\
\hline Bilobar & 7 & 5.6 & $3.804-7.396$ & & & & \\
\hline \multicolumn{8}{|l|}{ BCLC stage } \\
\hline$A$ & 20 & 7.5 & 5.893-9.107 & 0.639 & & & \\
\hline B & 12 & 7.6 & $2.338-12.862$ & & & & \\
\hline AFP level (ng/mL) & & & & & 0.032 & 2.345 & $1.075-5.118$ \\
\hline$<200$ & 15 & 9.8 & $0.000-21.879$ & 0.027 & & & \\
\hline$\geq 200$ & 17 & 7.2 & $4.477-9.923$ & & & & \\
\hline \multicolumn{8}{|l|}{ Child-pugh stage } \\
\hline$A$ & 31 & 8.3 & $5.900-10.700$ & 0.613 & & & \\
\hline B & 1 & 7.5 & & & & & \\
\hline
\end{tabular}




\begin{tabular}{lllll}
\hline AFP response $(\mathrm{ng} / \mathrm{mL})$ & & & & \\
$\geq 200$, no response & 15 & 7.2 & $3.792-10.608$ & 0.070 \\
$\geq 200$, response & 3 & 7.5 & $0.000-17.902$ & \\
$<200$ & 14 & 9.8 & $0.000-26.216$ & \\
\hline AST increase $>25 \%$ & & & & \\
Absent & 25 & 9.4 & $6.952-11.848$ & 0.136 \\
Present & 7 & 2.4 & $1.887-2.913$ & \\
\hline Child-Pugh increase & & & & \\
Absent & 21 & 9.4 & $7.157-11.643$ & 0.038 \\
Present & 11 & 7.2 & $4.395-10.005$ & \\
\hline Radiologic tumor response & & & & \\
Absent & 17 & 14.5 & $7.466-21.534$ & 0.151 \\
Present & 15 & 7.2 & $4.645-9.755$ & \\
\hline Number of TACE & & & & \\
2 & 18 & 4.9 & $0.000-12.592$ & 0.177 \\
$\geq 2$ & 14 & 11 & $7.700-14.300$ & \\
\hline Chemotherapy agents & & & & \\
Doxorubicin & 20 & 8.3 & $4.356-12.244$ & 0.665 \\
Csplatin & 3 & 7.5 & $3.179-11.821$ & \\
Doxorubicin/Carboplatin & 9 & 5.6 & $0.000-12.028$ & \\
\hline
\end{tabular}

analysis showed no significant association with OS because of their homogeneity. In large solitary HCC, meta-analysis of 9 studies (corresponding to 6,008) which conducted HR and retrospective study undergoing TACE reported significantly higher morbidity and lower $0 \mathrm{~S}$ in patients with tumor size $>5$ $\mathrm{cm}$ than those with $<5 \mathrm{~cm}(27,28)$. Nevertheless, HR was reported to be more effective and safer in patients with solitary huge nodule HCC than TACE. This report was in accordance with revised treatment recommendation for solitary huge nodule by the modified BCLC staging system from TACE to surgical intervention (HR or OLT) (14).

TACE may become a double-edged sword since chemoembolization process does not only induce radiological tumor response but also may provoke deterioration of liver function that potentiate liver-related death (17). Adverse event after TACE is the key reason to obviate further session but identifying high-risk patients before the event is still challenging. Some previous studies were validated an ART score to identify which patients will benefit and who will not. As original report, the ART score had successfully differentiated two groups ( 0 - 1.5 points; $\geq 2.5$ points) with distinct prognosis (median OS: 23.7 versus 6.6 months; $P<0.001$ ) (17). This study revealed similar results when the ART score was performed in all patients regardless time interval of TACE. H owever, sub-analysis in both TACE intervals $\leq 90$ Vs. $>90$ days and sequential assessment of the ART score (before TACE-3 and TACE-4 sessions) showed contrasting results. Nevertheless, we should note that lower ART score showed better survival outcome than those with higher ART score. Relatively small number of patients might be the cause of conflicting results.

The applicability of an ART score in decision making process for retreatment with TACE in Indonesian population need further studies since analysis results of single variable that consists the ART score in this study did not show significant association with OS. As described in Table 1, HBV infection is the most frequent etiology of HCC in our population. Although the data were not shown, abnormal liver enzyme was mostly found in patients suffered from chronic HBV infection, suggesting that AST level increase was not only related to TACE derived liver damage, but also affected by viral hepatitis infection. I n our institution, HCC patients with $\mathrm{HBV}$ infection who underwent TACE and have never been treated with an antiviral would receive nucleoside analogue as preemptive therapy at least 2 weeks before TACE treatment. Thus, we never know whether the stable HBV control had been achieved or not before TACE performed. Other clinical determinant that presented good value for predicting patient's prognosis in this study was baseline AFP levels (beforeTACE-1). W efound that baselineAFP level was an independent predictor associated with survival. It is not surprisingly since AFP has been well-established not only for diagnosis but also for monitoring treatment response, recurrence, and survival (29-31). AFP has capability to drive proliferation of liver cancer cell, tumor blood vessels conformation, enhance antiapoptosis effect of cancer cells, and induce the immune escapes (32). Many studies have shown that down-regulation of A FP can suppress its growth. Thus, high serum AFP level is correlated with more aggressive behavior and poorer prognosis of HCC (33). In contrast with those finding about AFP functions, in this study we observed that AFP levels was not correlated with tumor burdens (size, number, and extension) and radiological tumor response. The possible reason is due to the differences in cut-off determination for categorizing AFP and tumor burdens into a group, as in line with the previous report (34). Our study has several limitations. First, this study was a retrospective design carried out in a single center and relatively small number of samples. Second, there was a discrepancy of TACE characteristic, including time intervals between sessions, the number of TACE sessions, and chemotherapy agent obtained by patients in which might be lead biased results. Third, many patients were classified into BCLC stage $A$ as they had single nodule with good liver function and performance status even though had very large tumor size that might affect to survival. 


\section{CONCLUSION}

In conclusion, the ART score has potential to be a significant predictor of OS for HCC patients undergoing retreatment with TACE. Furthermore, the ART score must be implemented with caution in daily clinical setting since it has widely differenced in etiology of HCC, population characteristics, the number of samples, research methods, and characteristic of TACE used among studies. The combination of ART score and AFP levels may increase prognostic values in predicting survival of HCC patients who undergo multiple TACE. Further prospective research with a greater number of samples is needed.

\section{ACKNOWLED GMENTS}

This study did not received any funding nor grant.

\section{CONFLICT OF INTEREST}

The authors in this study declared that they do not have any conflict of interest with respect to this manuscript.

\section{REFERENCES}

1. Annisa, Zain LH, Loesnihari R. Protection status against hepatitis $B$ infection assessed fromanti-HBs level, history of vaccination andhistory of infection based on anti-HBc in medical students. In Institute of Physics Publishing; 2018.

2. Putera $E M, M$ arcia $D$, Firdarini I, A min $M$, Juniastuti J, Purwono PB, et al. Hepatitis B Serology Profiles On Children Aged 1-13 Years Old In Sumenep, M adura. IndonesJ Trop Infect Dis. 2012;3(2):61-4.

3. Tanadi MR, Lusida MI, Joewono HT. Proportion of HBsA g AND HBeAg Positive In M aternal Patients And Their HBsAg Positives Babies With Immunoprophylaxis of $\mathrm{Hbv}$ Immunization In Dr. Soetomo General Hospital, Surabaya. Indones J Trop Infect Dis. 2017;6(4):79-83.

4. Lubis HP, Halim B, A denin I, Rusda M, Prasetiawan E. $H$ epatitis $B$ virus infection on male partner has negative impact on in-vitro fertilization. In: IOP Conference Series Earth and Environmental Science. Institute of Physics Publishing; 2018.

5. Gunardi H, Iskandar MY, Turyadi, Ie SI, Dwipoerwantoro PG, Gani RA, et al. Hepatitis B virus infection in children of $\mathrm{HBV}$-related chronic liver disease patients: a study of intra-familial HBV transmission. Hepatol Int. 2017;11(1):96-104.

6. Darmawan E, Turyadi, El-Khobar KE, Nursanty NKD, Thedja MD, Muljono DH. Seroepidemiology and occult hepatitis B virus infection in young adults in Banjarmasin, Indonesia. J M ed Virol. 2015;87(2):199_ 207.

7. Bray F, Ferlay J, Soerjomataram I. Global Cancer Statistics 2018: GLOBOCAN Estimates of Incidence and Mortality Worldwide for 36 Cancers in 185 Countries. CA Cancer J Clin. 2018;68:394-424.

8. Siregar GA, Buulolo BA. Factors associated with tumor size of hepatocellular carcinoma. In: IOP Conference Series Earth and Environmental Science. Institute of Physics Publishing; 2018.
9. Zhu RX, Seto W, Lai C, Yuen M. Epidemiology of Hepatocellular Carcinoma in the Asia-Pacific Region. Gut Liver. 2016;10(3):332-9.

10. Muljono DH. Epidemiology of Hepatitis $B$ and $C$ in Republic of Indonesia. Euroasian J Hepatogastroenterol. 2017;7(June):55-9.

11. Pascual S, Herrera I, I rurzun J, Pascual S, Herrera I, Irurzun J, et al. 2016 Hepatocellular Carcinoma: Global view New advances in hepatocellular carcinoma. W orld J H epatol. 2016;8(9):421-38.

12. M eer $\mathrm{S} V$ an, Man RA De, Siersema PD, Erpecum KJ $V$ an, M eer S V an, Siersema PD, et al. Surveillance for hepatocellular carcinoma in chronic liver disease: Evidence and controversies. World J Gastroenterol. 2013;19(40):6744-56.

13. Bruix J, Sherman M. AASLD PRACTICE GUIDELINE $M$ anagement of Hepatocellular Carcinoma: An U pdate. Hepatology. 2010;53:1020-2.

14. Galle PR, Forner A, Llovet JM, M azzaferro V, Piscaglia F, Raoul JL, et al. EASL Clinical Practice Guidelines: $M$ anagement of hepatocellular carcinoma. J Hepatol. 2018;69(1):182-236.

15. Ahmed S, Souza N N De, Qiao W, Kasai M, Keem LJ, Shelat VG. Q uality of Life in H epatocellular Carcinoma Patients Treated with Transarterial Chemoembolization. HBP Surg. 2016;

16. Terzi E, Golfieri R, Piscaglia F, Galassi M, Dazzi A, Leoni $S$, et al. Response rate and clinical outcome of HCC after first and repeated cTACE performed " on demand."'J Hepatol. 2012;57(6):1258-67.

17. Sieghart W, Hucke F, Peck-Radosavljevic $M$. Transarterial chemoembolization: Modalities, indication, and patient selection. J Hepatol. 2015;62(5):1187_95.

18. Sieghart W, Hucke F, Pinter M, Graziadei I, Vogel W, Müller $C$, et al. The ART of decision making: Retreatment with transarterial chemoembolization in patients with hepatocellular carcinoma. Hepatology. 2013;57(6):2261-73.

19. Hucke F, Sieghart W, Pinter M, Graziadei I, V ogel W, Müller $C$, et al. The ART-strategy: Sequential assessment of the ART score predicts outcome of patients with hepatocellular carcinoma re treated with TACE. J Hepatol. 2014;60(1):118-26.

20. Terzi $E$, Terenzi L, Venerandi L, Croci L, Renzulli $M$, M osconi C, et al. The ART score is not effectiveto select patients for transarterial chemoembolization retreatment in an Italian series. Dig Dis. 2014;32(6):711-6.

21. Arizumi $T$, Ueshima $K$, I wanishi $M$, Minami $T$, Chishina $H$, Kono $M$, et al. Evaluation of ART Scores for Repeated Transarterial Chemoembolization in Japanese Patients with Hepatocellular Carcinoma. Oncology. 2015;89(suppl 2):4-10.

22. Tseng CL, Lai WJ, Huang CJ, Huang YH, Su CW, Lee $I C$, et al. The effectiveness of ART score in selecting patients for transarterial chemoembolization retreatment a cohort study in Taiwan. Med (United States). 2015;94(47):e1659.

23. HaY, LeeJB, Shim JH, Kim KM, Lim YS, Yoon HK, et 
al. Validation and reappraisal of the assessment for retreatment with transarterial chemoembolization score for unresectable non-metastatic hepatocellular carcinoma in a hepatitis b virus-endemic region. Eur Radiol. 2016;26(10):3510-8.

24. Yin $W L, Y e Q, W$ ang $F M$, Liang J, Xu BG, Zhang $X$, et al. ART score and hepatocellular carcinoma: An appraisal of its applicability. Clin Res Hepatol Gastroenterol. 2016;40(6):705-14.

25. Pipa-Muñiz M, Castells $L$, Pascual $S$, FernándezCastroagudín J, Díez-M iranda I, Irurzun J, et al. The ART-SCORE is not an effective tool for optimizing patient selection for DEB-TACE retreatment. A multicentre Spanish study. Gastroenterol Hepatol. 2017:40(8):515-24.

26. Abbasi AH, Abid S, A wan S. Role of Assessment for Retreatment with Transarterial Chemoembolization Score in Decision of Retreatment with Trans-arterial Chemoembolization Sessions in Patients with Hepatocellular Carcinoma. J Ayub Med Coll Abbottabad. 2017;29(3):378-83.

27. Jiang J, Zhong J, Zheng $M$, Cucchetti A, Luo C. Selection of patients with solitary hepatocellular carcinoma for hepatic resection : reassessment of a 5$\mathrm{cm}$ tumor size cut-off. Int J Clin Exp Med. 2017;10(4):6283-92.

28. Terzi E, Piscaglia F, Forlani L, M osconi C, Renzulli M, Bolondi $L$, et al. TACE performed in patients with a single nodule of Hepatocellular Carcinoma. BMC Cancer. 2014;14:601.

29. Bai $D$, Zhang $C$, Chen $P$, Jin S, Jiang G. The prognostic correlation of AFP level at diagnosis with pathological grade, progression, and survival of patients with hepatocellular carcinoma. Sci Rep. 2017; (September):1-9.

30. Xu XS, Qu K LC. Highlights for $\alpha$-fetoprotein in determining prognosis and.pdf. World J Gastroenterol. 2012;18(48):7242-50.

31. Schraiber S, Mattos AA De, Zanotelli ML, Pio G, Cantisani C. Alpha-fetoprotein Level Predicts Recurrence After Transplantation in Hepatocellular Carcinoma. M edicine (Baltimore). 2016;95(3):1-7.

32. Wang $X$, Wang $Q$. Alpha-Fetoprotein and Hepatocellular Carcinoma Immunity. Can J Gastroenterol Hepatol. 2018;2018:1-8.

33. Toro A, Ardiri A M M . Effect of pre and post treatment afetoprotein levels and tumor size on survival of patients with hepatocellular carcinoma treated by resection, transarterial chemoembolization or radiofrequency ablation: a retrospective study. BMC Surg. 2014;14:40.

34. Shabbir K, Shehzad A NM. Association of serum alpha fetoprotein (AFP) levels with size of hepatocellular carcinoma. Pak Armed Forces M ed J. 2019;69(1):71-5. 